\title{
Association of Mothers' Parenting Practices and Clinical and Reported Oral Health Outcomes in Primary-school Age Girls
}

\author{
Nora Saud Alkaltham ${ }^{1}$, Lujain Ali Alzahrani², Nada Khalid Alhorish², Maha El Tantawi ${ }^{3}$ \\ ${ }^{1}$ Department of Substitutive Dental Science, Imam Abdulrahman Bin Faisal University, Dammam, Saudi Arabia, \\ ${ }^{2}$ General Practitioners, Imam Abdulrahman Bin Faisal University, Dammam, Saudi Arabia, ${ }^{3}$ Department of \\ Pediatric Dentistry and Dental Public Health, Alexandria University, Alexandria, Egypt
}

\begin{abstract}
Purpose: This study was to assess the relationship between mothers' positive parenting, disciplining, and authoritative parenting practices and clinically assessed and child-reported oral health in a primary school-age girl. Methods: A crosssectional study included girls in primary schools in the Eastern Province, Saudi Arabia, in 2018. Clinical examination assessed caries experience in primary and permanent teeth, plaque, and gingivitis. The girls responded to questionnaires assessing sociodemographic background, dental behaviors, and reported oral health outcomes. Three questionnaires assessed the frequency of disciplining practices, positive parenting practices, and authoritative parenting. Multivariate general linear regression was used to assess the relationship between outcome variables (clinical and child-reported outcomes) and explanatory variables (parenting practices) controlling for confounders (sociodemographic variables and dental behaviors). Results: The response rate was $92.5 \%$ (284/307). The girls were 11 years on average, with $62 \%$ nonuniversity educated fathers and mothers. Frequent disciplining was associated with impact on daily life $(B=0.35,95 \%$ confidence interval $[\mathrm{Cl}]=0.05,0.65)$ and poorer perceived dental health $(\mathrm{B}=-0.20,95 \% \mathrm{Cl}=-0.39,-0.001)$. Authoritative parenting was associated with fewer permanent teeth with caries experience $(\mathrm{B}=-0.07,95 \% \mathrm{Cl}=-0.12,-0.02)$. Frequent positive parenting practices were associated with more sound primary teeth $(\mathrm{B}=1.46,95 \% \mathrm{Cl}=0.15,2.77)$, fewer sound permanent teeth $(B=-2.66,95 \% \mathrm{Cl}=-4.36,-0.96)$, and better perceived dental health $(\mathrm{B}=0.34,95 \% \mathrm{Cl}=0.09,0.60)$. Conclusion: Authoritative parenting was associated with good clinical oral health outcomes and frequent disciplining was negatively associated with child-reported outcomes. Frequent positive parenting practices had a positive association with the health of primary teeth but not permanent teeth.
\end{abstract}

Key words: Caries, oral health behavior, parenting practices

\section{INTRODUCTION}

Parents are the main influencers of their children's health; they make decision about the quality of healthcare their children receive, food they eat, physical activity they perform,

\begin{tabular}{|l|l|}
\hline \multicolumn{2}{|c|}{ Access this article online } \\
\hline Publisher & $\begin{array}{l}\text { Website: } \\
\text { www.ijdms.in }\end{array}$ \\
\hline & DOI: 10.30954/IJDMS.1.2020.7 \\
\hline
\end{tabular}

and shape their surrounding environments. ${ }^{[1,2]}$ The impact of parents on their children's oral health occurs through many ways. More educated mothers have better perceptions of the availability and use of health care information. ${ }^{[1]}$ Maternal factors such as mother's age, education, occupation, oral health behavior, knowledge, and attitudes are associated with the oral health of their children. ${ }^{[3]}$ Mothers from higher socioeconomic levels had children with a greater likelihood of tooth brushing twice a day. ${ }^{[2]}$ Higher levels of caries were found in children from single-parent families, larger households, and in children of higher birth order. ${ }^{[4]}$ Research showed that the family and home environment played a central role in the promotion of oral health ${ }^{[2]}$ and

Address for Correspondence:

Nora Saud Alkaltham, Department of Substitutive Dental Science, Imam Abdulrahman Bin Faisal University, Dammam, Saudi Arabia. Phone: +966560607711. E-mail: nsalkaltham@gmail.com

Submission: 19 May 2020; Revision: 16 June 2020; Acceptance: 29 June 2020 
that parental monitoring and support affect children's health. ${ }^{[1,5]}$

Previous studies assessed the relationship between parenting styles and oral health practices such as behavior during dental visits, ${ }^{[6]}$ visiting the dentist, ${ }^{[7,8]}$ oral hygiene behaviors, ${ }^{[7-10]}$ and sugar consumption. ${ }^{[7,8]}$ In addition to clinical outcomes such as plaque accumulation, ${ }^{[11,12]}$ caries ${ }^{[6,7,9]}$ early childhood caries, ${ }^{[8,13]}$ gingivitis, ${ }^{[12]}$ and patient-reported outcomes such as quality of life. ${ }^{[10]}$ These studies had different conclusions that depended, among other things, on the population in which the study was conducted.

Parenting practices are affected by the cultural context and differ among countries. Generational, social, and culture of caregiving play formative roles in generating parenting cognitions and guiding parenting practices. ${ }^{[14]}$ For example, American and Japanese parents' values differ; American mothers try to promote autonomy, assertiveness, verbal competence, and self-actualization in their children, whereas Japanese mothers try to promote emotional maturity, selfcontrol, social courtesy, and interdependence. ${ }^{[15,16]}$ These differences are reflected on the impact of parenting practices on oral health. For example, Dabawala et al. reported that they were not able to find a significant association between ECC and authoritative parenting style among Indian children because this parenting style was widely prevalent in all parents regardless of whether the child had or not ECC. ${ }^{[8]}$ On the other hand, Howenstein et al. reported a significant difference between American children in caries and behavior during dental visits based on authoritative parenting. ${ }^{[6]}$

Previous studies assessing the relationship between oral health practices and outcomes were conducted in Lithuania; ${ }^{[11]}$ the US; ${ }^{[6]}$ the Netherlands; ${ }^{[9,13]}$ and India, ${ }^{[7,8,10,12]}$ with no adequate information about the impact of parenting practices on children's oral health in Arab countries. In addition, most of these studies were conducted among children in early adolescence when they are in middle school ${ }^{[7,10-12]}$ or among preschool children. ${ }^{[6,8,9]}$ There is inadequate information about the association between parenting practices and oral health in late childhood when children join a primary school (6-12 year old); an age at which they start to interact with the world outside their home and when influences other than those of parents begin to shape their behaviors.

The present study aimed to fill this knowledge gap by assessing the relationship between mothers' parenting practices and clinically assessed and child-reported oral outcomes among girls in primary schools in Dammam and Khobar, Eastern Province, Saudi Arabia. The hypothesis of the study was that there will be no association between children clinical and reported oral health outcomes and parenting practice.

\section{METHODS}

This cross-sectional study was conducted in January to April 2018 in three primary schools in Dammam, Saudi Arabia. The schools were selected by the Directorate of Education of the Eastern Province in response to the researcher's request to assign primary schools in this area for the study purpose. Participants were included if they were studying in a public primary school in the study area, were free from medical conditions that may affect their oral health, and their parents consented to their participation. Due to gender segregation, only girls' schools could be accessed by the study team consisting of female investigators. Sample size was based on assuming alpha error $=5 \%$ and study power $=80 \% \cdot{ }^{[17]}$ Reported that the lowest encouragement scores (corresponding to positive parenting in the present study) in caries-free and caries affected children were 62 and 59, respectively, $\mathrm{SD}=8.7$. The total required sample size was calculated to be 264 and increased by $10 \%$ to 290 to allow for non-response. ${ }^{[18]}$ The study was conducted after obtaining the approval of the Institutional Review Board of Imam Abdulrahman Bin Faisal University (IRB-2017-02-048) and in full accordance with the Helsinki Declaration. A letter was sent to parents explaining the study purpose and asking for consent. Only children whose parents agreed were included in the study.

Clinical outcomes were assessed using an oral examination for caries experience where caries was diagnosed at the cavitation level using the World Health Organization criteria. ${ }^{[19]}$ Filled teeth and teeth missing due to caries were recorded in primary and permanent teeth. Plaque accumulation and gingival inflammation were assessed on six index teeth using the indices of Loe and Silness. ${ }^{[20,21]}$ Children were examined under daylight conditions using disposable instruments by three calibrated examiners with good agreement with a gold standard examiner (Kappa >0.6).

Child-reported outcomes and confounders were assessed using the WHO child oral health questionnaire including sociodemographic factors (age and parental university education), oral hygiene practices (brushing twice daily), whether the child visited the dentist for regular checkups during the last year and the frequency on a scale from never 1 to more than once daily 6 of consuming seven types of sugar products. Self-perceived dental and gingival health were each assessed on a scale from poor 1 to very good 4 . The impact of oral health on daily life was assessed using six statements using yes/no answers. Three other questionnaires were used to assess the exposures; parenting practices. These included the (a) discipline interview where the child indicated the frequency on a scale from never 1 to almost every week 5 of 8 disciplining practices her mother used (parenting across culture) ${ }^{[22]}$, (b) the authoritative parenting index in 2 sections: 9 responsiveness statements and 7 demandingness statements where the child indicated 
on a scale from just like her 1 to not like her 4 how much the statements described her mother, ${ }^{[23]}$ and (c) the positive parenting practices questionnaire where the child indicated the frequency from never 1 to often 4 of 5 positive things her mother used to show her approval of what the child did. ${ }^{[24]}$ The questionnaires were translated to Arabic and pilot tested on 20 children to ensure clarity. ${ }^{[19]}$ The questionnaires were interview-administered during the break and children responses were recorded in paper-based forms. Examination and interview were conducted in the same visit.

Sugar frequency score was the sum of the frequency of the sugary products and ranged from 7-42 with higher values indicating more frequent sugar consumption. Plaque and gingival indices scores for the six index teeth were averaged to produce individual-level scores. DMF/df scores were created by adding the count of decayed, missing, and filled teeth as applicable. The score for oral health impact on life was the count of "yes" responses to the six statements and ranged from 0 to 6 with higher scores indicating worse impact on daily life. The Disciplining Interview score was the average of the eight statements' scores and ranged from 1 to 5 (more frequent disciplining). The authoritative parenting index score was calculated after reverse coding the scores of responsiveness and it was the sum of scores of all 16 statements, ranging from 16 to 64 with higher scores indicating more authoritative parenting. The positive parenting practices score was the mean of the five statements and ranged from 1 to 4 , indicating more frequent positive parenting practices.

The dependent variables were six clinically-assessed outcomes (plaque accumulation, gingival inflammation, number of sound primary teeth, number of primary teeth with caries experience, number of sound permanent teeth, and number of permanent teeth with caries experience) and three child-reported outcomes: Impact of oral health on life, perceived dental health, and perceived gingival health. The independent variables were three scores of parenting practices (disciplining frequency, positive parenting practices frequency, and authoritative parenting index). Multivariate general linear model was used to assess the relationship between the dependent and independent variables controlling for confounders (age, parental education, brushing twice daily, sugar frequency score, and regular dental checkups). ${ }^{[25]}$ We calculated regression coefficients (B), 95\% confidence intervals (CI), and $P$ values using IBM SPSS for Windows version 22.0 (IBM Corp., Armonk, N.Y., USA). Significance level was set at $5 \%$.

\section{RESULTS}

Consents were received from 307 parents allowing their children to participate in the study and 284 children responded completely to the questionnaires (response rate $=92.5 \%$ ). Table 1 shows that participants were 11 years old on average and most of them had non-universityeducated fathers $(62 \%)$ and mothers $(62.3 \%)$. Most of them brushed twice daily (55.2\%) and did not visit the dentist regular last year (77\%). They reported moderate sugar consumption frequency $($ mean $=23.39 / 42)$, moderate disciplining frequency (mean $=2.56 / 5$ ), above-average authoritative parenting practices (mean $=39.83 / 64)$, and frequent positive parenting practices $($ mean $=3.30 / 4)$.

Table 2 shows that the participants had good oral hygiene (mean plaque index $=0.96$ and mean gingival index $=0.60)$. On average, they had 5.29 sound primary

Table 1: Sociodemographic, dental, and parenting characteristics of participating girls $(n=284)$

\begin{tabular}{lcc}
\hline Age & Mean (SD) & $\mathbf{1 1 . 0 ( 0 . 9 )}$ \\
\hline University-educated father & Yes: $n(\%)$ & $108(38)$ \\
& No: $n(\%)$ & $176(62)$ \\
University-educated mother & Yes: $n(\%)$ & $107(37.7)$ \\
& No: $n(\%)$ & $177(62.3)$ \\
Brushes twice daily & Yes: $n(\%)$ & $155(55.2)$ \\
& No: $n(\%)$ & $126(44.8)$ \\
Regular checkups & Yes: $n(\%)$ & $53(23)$ \\
& No: $n(\%)$ & $177(77)$ \\
Sugars frequency score & Mean (SD) & $23.39(6.72)$ \\
(7-42, higher is more frequent) & Mean (SD) & $2.56(0.74)$ \\
$\begin{array}{l}\text { Discipline frequency score } \\
\text { (1-5, higher is more frequent) }\end{array}$ & Mean (SD) & $39.83(4.16)$ \\
$\begin{array}{l}\text { Authoritative parenting index } \\
\text { (16-64, higher is more authoritative) }\end{array}$ & Mean (SD) & $3.30(0.58)$ \\
$\begin{array}{l}\text { Positive parenting practices } \\
(1-4, \text { higher is more frequent) }\end{array}$ & & \\
\hline
\end{tabular}

Table 2: Clinically assessed and child-reported oral health outcomes

\begin{tabular}{lll}
\hline Outcomes & Mean (SD) \\
\hline Clinically- & Plaque index & $0.96(0.74)$ \\
assessed & Gingival index & $0.60(0.60)$ \\
outcomes & Number of sound primary teeth (s) & $5.29(4.92)$ \\
& Number of decayed primary teeth (d) & $0.82(1.57)$ \\
& Number of filled primary teeth (f) & $0.07(0.40)$ \\
& Number of primary teeth with caries & $0.9(1.75)$ \\
& experience (df) & \\
& Number of sound permanent teeth (S) & $19.40(6.79)$ \\
& Number of decayed permanent & $0.48(1.14)$ \\
& teeth (D) & $0.04(0.28)$ \\
& Number of missing permanent & \\
& teeth (M) & $0.06(0.36)$ \\
& Number of filled permanent teeth (F) & $0.59(1.27)$ \\
& Number of permanent teeth with caries & \\
& experience (DMF) & \\
Child- & Self-perceived dental health & $2.82(0.92)$ \\
reported & (1-4, higher is better) & \\
outcomes & Self-perceived gum health (1-4, higher & $3.01(0.94)$ \\
& is better) & \\
& $\begin{array}{l}\text { Oral health impact on life (0-6, higher } \\
\text { is worse impact) }\end{array}$ & $1.48(1.40)$ \\
\hline
\end{tabular}


teeth, 1.05 primary teeth with caries experience, 19.4 sound permanent teeth, and 0.59 permanent teeth with caries experience. Participants had above average perception of dental health (mean $=2.82 / 4$ ) and gingival health $($ mean $=3.01 / 4)$ with minimal impact of oral health on daily life $($ mean $=1.48 / 6)$.

Table 3 shows the association between the three parenting practices and oral health outcomes. Higher disciplining frequency was not significantly associated with clinically assessed outcomes but significantly associated with childreported outcomes: Greater impact of oral health on daily life $(\mathrm{B}=0.35,95 \% \mathrm{CI}=0.05,0.65)$ and poorer perceived dental health $(\mathrm{B}=-0.20,95 \% \mathrm{CI}=-0.39,-0.001)$. Authoritative parenting was significantly associated with a clinical outcome; fewer permanent teeth with caries experience $(\mathrm{B}=-0.07,95 \% \mathrm{CI}=-0.12,-0.02)$. More frequent positive parenting practices were significantly associated with two clinical outcomes: Greater number of sound primary teeth $(\mathrm{B}=1.46,95 \% \mathrm{CI}=0.15,2.77)$ and fewer sound permanent teeth $(\mathrm{B}=-2.66,95 \% \mathrm{CI}=-4.36$, $-0.96)$ and with child-reported outcome; better perceived dental health $(\mathrm{B}=0.34,95 \% \mathrm{CI}=0.09,0.60)$.

\section{DISCUSSION}

The present study showed that frequent disciplining was associated with negative child-reported outcomes, whereas more authoritative parenting was associated with fewer permanent teeth with caries experience. On the other hand, more frequent positive parenting was associated with more sound primary teeth and better perception of dental health, but fewer sound permanent teeth. These findings provide partial support to the study hypothesis and have implications for health education messages targeting mothers of girls at the primary school age. They should be advised that in this age, authoritative parenting providing firm guidance may promote oral health and a positive outlook of children about their teeth and that frequent positive parenting practices are needed in different degrees at various stages of child development so that by the time permanent teeth are all erupted, these practices may need to be tuned down. Pending further investigation in longitudinal studies, our study suggests that maternal practices that are supportive, firm, and supervising are associated with better oral health outcomes in this age.

In the present study, the higher disciplining frequency was associated with worse perceived dental health and more frequent positive parenting practices were associated with better-perceived health. These findings agree with Kumar et al. who reported that, among a group of 12 -year-old children from India, positive parenting was associate with the less negative impact of oral health on daily life $(B=-0.106)$ whereas power assertive parenting was associated with worse impact $(B=0.103) .{ }^{[10]}$ It is important to note that in the present study, these associations persisted after controlling for the number of carious teeth suggesting that the association with parenting practices extended beyond the effect of untreated caries and dental pain. This disagrees with Banu et al., who reported an association between dental pain because of oral diseases and perception of oral health. ${ }^{[26]}$ Our findings agree with research showing that 12-year-old children from the Netherlands had less dissatisfaction with their bodies when their relationship with their mothers was positive. ${ }^{[27]}$

In the present study, positive parenting practices were associated with more sound primary teeth and fewer sound permanent teeth. The positive impact on primary dentition disagrees with Duijster et al. who reported no difference between caries-free Dutch, Moroccan, and Turkish 6-yearold children who were controls and cases who had dmft $\geq 4$ in parent-reported positive parenting score (mean = 26.1 and $26.4, P=0.59) \cdot{ }^{[17]}$ However, the present study results are consistent with them in the case of researcherobservation of parents' behavior where there was a higher encouragement score in controls (mean $=78.7$ ) than in cases $($ mean $=73.7)$. The reversed significant relationship between

Table 3: Association of parenting practices with clinically assessed and child-reported oral health outcomes

\begin{tabular}{|c|c|c|c|c|}
\hline \multirow[t]{2}{*}{ Factors } & \multicolumn{3}{|c|}{ B (95\% Cl) } & \multirow[t]{2}{*}{$P$ value } \\
\hline & Disciplining & Positive parenting & Authoritative parenting & \\
\hline \multicolumn{5}{|l|}{ Clinically assessed outcomes } \\
\hline Plaque & $0.02(-0.16,0.20)$ & $-0.11(-0.34,0.12)$ & $-0.01(-0.04,0.02)$ & 0.92 \\
\hline Gingivitis & $0.03(-0.10,0.17)$ & $-0.002(-0.18,0.18)$ & $-0.02(-0.04,0.008)$ & 0.48 \\
\hline Number of sound primary teeth & $-0.62(-1.62,0.38)$ & $1.46(0.15,2.77)^{*}$ & $-0.02(-0.18,0.15)$ & $<0.0001^{*}$ \\
\hline Number of primary teeth with caries experience & $-0.37(-0.79,0.06)$ & $0.15(-0.40,0.70)$ & $-0.06(-0.13,0.02)$ & $0.02^{*}$ \\
\hline Number of sound permanent teeth & $1.27(-0.03,2.57)$ & $-2.66(-4.36,-0.96)^{*}$ & $0.19(-0.03,0.41)$ & $<0.0001^{\star}$ \\
\hline Number of permanent teeth with caries experience & $0.06(-0.24,0.36)$ & $0.03(-0.37,0.43)$ & $-0.07(-0.12,-0.02)^{*}$ & $0.02^{*}$ \\
\hline \multicolumn{5}{|l|}{ Child-reported outcomes } \\
\hline Impact on life & $0.35(0.05,0.65)^{*}$ & $0.05(-0.34,0.43)$ & $0.01(-0.04,0.06)$ & $0.03^{*}$ \\
\hline Perceived dental health & $-0.20(-0.39,-0.001)^{*}$ & $0.34(0.09,0.60)^{*}$ & $0.001(-0.03,0.03)$ & $<0.0001^{\star}$ \\
\hline Perceived gum health & $-0.11(-0.33,0.12)$ & $0.21(-0.09,0.50)$ & $-0.002(-0.04,0.04)$ & 0.35 \\
\hline
\end{tabular}

B: Regression estimate, $\mathrm{Cl}$ : Confidence interval, "statistically significant at $P<0.05$. Controlling for age, parental education, brushing twice daily, sugar frequency score, and having regular dental checkups. 
positive parenting practices and fewer sound permanent teeth suggests difference by dentition probably because of child development. The age of the children included in the present study is the time at which the praise they receive might affect their performance. ${ }^{[28,29]}$ High frequency of positive parenting practices may indicate inflated praise by parents which ${ }^{[29]}$ reported to predict low self-esteem possibly through lowering children's perceived competence to perform tasks. In the present study, this might have reduced the thoroughness of oral self-care practices, although their frequency was not affected. On the other hand, in the present study, authoritative parenting was associated with fewer primary and permanent teeth with caries experience, although this was significant only in permanent teeth. This partially agrees with Howenstein et al., who reported a significant association between authoritative parenting and less caries in primary teeth. The difference may be explained by the younger age of the children in Howenstein et al.'s study (3-6 years old) where they are expected to have a greater number of primary teeth providing higher power to detect differences than in the present study where only a few primary teeth remain at this late childhood stage. ${ }^{[6]}$ The preventive effect of authoritative parenting against caries may be attributed to greater parental monitoring of child oral health behaviors. ${ }^{[30]}$ The present study fills a knowledge gap by providing evidence suggesting that the preventive effect of authoritative parenting is sustained till the permanent dentition stage.

The present study is limited by its cross-sectional design that can suggest but not prove causality and by including only girls because of cultural and logistic considerations. Our findings thus apply to girls in the primary school age from low to middle socioeconomic backgrounds with moderate oral health practices in similar cultural settings. The observed associations may differ in direction or strength among boys or among children from different socioeconomic status or those in settings where different parenting practices prevail.

Future research, including boys and girls, would help in a greater generalization of findings. Furthermore, longitudinal studies can support causality and would allow the assessment of parenting practices as children grow and how this affects children's oral health in a life-course approach. Studying differences in the impact of fathers' and mothers' practices on children's oral health would provide a better perspective about the effect of home environment on oral health.

\section{REFERENCES}

1. Case A, Paxson C. Parental behavior and child health. Health Aff (Millwood) 2002;21:164-78.

2. Levin KA, Currie C. Adolescent toothbrushing and the home environment: Sociodemographic factors, family relationships and mealtime routines and disorganisation. Community Dent Oral Epidemiol 2010;8:10-8.

3. Poutanen R, Lahti S, Tolvanen M, Hausen H. Parental influence on children's oral health-related behavior. Acta Odontol Scand
2006;64:286-92.

4. Skeie MS, Riordan PJ, Klock KS, Espelid I. Parental risk attitudes and caries-related behaviours among immigrant and western native children in Oslo. Community Dent Oral Epidemiol 2006;34:103-13.

5. Duijster D, O’Malley L, Elison S, Van Loveren C, Marcenes W, Adair PM, et al. Family relationships as an explanatory variable in childhood dental caries: A systematic review of measures. Caries Res 2013;47 Suppl 1:22-39.

6. Howenstein J, Kumar A, Casamassimo PS, McTigue D, Coury D, Yin H. Correlating parenting styles with child behavior and caries. Pediatr Dent 2015;37:59-64.

7. Kumar S, Tadakamadla J, Zimmer-Gembeck MJ, Kroon J, Lalloo R, Johnson NW. Parenting practices and children's dental caries experience: A structural equation modelling approach. Community Dent Oral Epidemiol 2017;45:552-8.

8. Dabawala S, Suprabha BS, Shenoy R, Rao A, Shah N. Parenting style and oral health practices in early childhood caries: A case-control study. Int J Paediatr Dent 2017;27:135-44.

9. Duijster D, Verrips GH, Van Loveren C. The role of family functioning in childhood dental caries. Community Dent Oral Epidemiol 2014;42:193-205.

10. Kumar S, Zimmer-Gembeck MJ, Kroon J, Lalloo R, Johnson NW. The role of parental rearing practices and family demographics on oral health-related quality of life in children. Qual Life Res 2017;26:2229-36.

11. Aleksejuniene J, Brukiene V. Parenting style, locus of control, and oral hygiene in adolescents. Medicina (Kaunas) 2012;48:102-8.

12. Kumar S, Tadakamadla J, Zimmer-Gembeck M, Kroon J, Lalloo R, Johnson NW. The effect of parenting practices on the severity of gingival bleeding in children. J Periodontol 2017;88:744-51.

13. De Jong-Lenters M, Duijster D, Bruist MA, Thijssen J, De Ruiter C. The relationship between parenting, family interaction and childhood dental caries: A case-control study. Soc Sci Med 2014;116:49-55.

14. Cole M, Cagigas XE. Cognition. In: Handbook of Cultural Developmental Science. New York: Psychology Press; 2010. p. 127-42. Available from: http://lchc.ucsd.edu/People/MCole/ Cognition.pdf. [Last accessed 2020 Aug 17].

15. Bornstein MH. Cultural approaches to parenting. Parent Sci Pract 2012;12:212-21.

16. Morelli GA, Rothbaum F. Situating the child in context: Attachment relationships and self-regulation in different cultures. In: Handbook of Cultural Psychology. New York: The Guilford Press; 2007.

17. Duijster D, De Jong-Lenters M, De Ruiter C, Thijssen J, Van Loveren C, Verrips E. Parental and family-related influences on dental caries in children of Dutch, Moroccan and Turkish origin. Community Dent Oral Epidemiol 2015;43:152-62.

18. Chow SC, Wang H, Shao J. Sample Size Calculations in Clinical Research. United Kingdom: Taylor \& Francis; 2007.

19. World Health Organization. Oral Health Surveys-Basic Methods. $5^{\text {th }}$ ed. Geneva: World Health Organization; 2013.

20. Silness J, Löe H. Periodontal disease in pregnancy. II. Correlation between oral hygiene and periodontal condtion. Acta Odontol Scand 1964;22:121-35.

21. Löe H, Silness J. Periodontal disease in pregnancy. I. Prevalence and severity. Acta Odontol Scand 1963;21:533-51.

22. Denzin NK, Lincoln YS, Giardina MD. Disciplining qualitative research. Int J Qual Stud Educ 2006;19:769-82.

23. Jackson C, Henriksen L, Foshee VA. The authoritative parenting index: Predicting health risk behaviors among children and adolescents. Heal Educ Behav 1998;25:319-37.

24. Krohn MD, Stern SB, Thornberry TP, Jang SJ. The measurement of family process variables: The effect of adolescent and parent perceptions of family life on delinquent behavior.J Quant Criminol 1992;8:287-315.

25. Afifi AA, Clark V. Computer-aided multivariate analysis. J Am Stat Assoc 2006;39:875-6. 
26. Banu A, Serban C, Pricop M, Urechescu H, Vlaicu B. Dental health between self-perception, clinical evaluation and body image dissatisfaction-a cross-sectional study in mixed dentition prepubertal children. BMC Oral Health 2018;18:74.

27. De Vries DA, Vossen HG, Kolk-van der Boom P. Social media and body dissatisfaction: Investigating the attenuating role of positive parent-adolescent relationships. J Youth Adolesc 2019;48:527-36.

28. Dweck CS. Development of Achievement Motivation. United States: Academic Press; 2002.

29. Brummelman E, Nelemans SA, Thomaes S, de Castro BO. When parents' praise inflates, children's self-esteem deflates. Child Dev 2017;88:1799-809.
30. Levin A, Sokal-Gutierrez K, Hargrave A, Funsch E, Hoeft KS Maintaining traditions: A qualitative study of early childhood caries risk and protective factors in an indigenous community. Int J Environ Res Public Health 2017;14:907.

How to cite this article: Alkaltham NS, Alzahrani LA, Alhorish NK, El Tantawi M. Association of Mothers' Parenting Practices and Clinical and Reported Oral Health Outcomes in Primary-School Age Girls. Int J Dent Med Spec 2020;7(1):20-25.

Source of Support: None; Conflicts of Interest: None 